\title{
FEATURES OF A CLINICALLY NORMAL OPTIC DISC*
}

BY

M. FORD

King Edward VII Hospital, Windsor

AND

M. SARWAR

United Oxford Hospitals

We felt that a survey and analysis of the features of normal optic discs could perhaps be rewarding, as such a study had not been carried out, as far as we knew, since the work of Thompson (1920), Picard (1921, 1923), and Bednarski (1925) (Williamson-Noble, 1961).

We were of the opinion that to obtain reliable results the study must be confined to simple points observed in the course of a routine examination. The following criteria were to be followed by each observer independently, and no comparison of results was to be made until the end of the survey:

(1) No pathological discs were to be included.

(2) Gross dissimilarity between normal discs in the two eyes was to be excluded.

(3) The margins, shape, and size of the disc were not to be recorded.

(4) Records were to be kept of the presence of:

(a) Venous pulsation.

(b) Glial tissue in and around the centre of the disc.

(c) Lamina cribrosa.

(d) Physiological cup and its size in relation to the disc, i.e. whether less than 20 per cent. of the disc area (designated as "small physiological cup") or more than 20 per cent. of the disc area (designated "physiological cup").

(e) Configuration of the cup, i.e. whether shallow or shelved.

$(f)$ Refractive error.

Records were kept for 5,006 patients whose ages ranged from 5 to 85 years.

The results when analysed as percentages of the total for the points mentioned yielded the following information:

(a) Venous pulsation was present in approximately 14.7 per cent.

(b) Glial tissue was present in approximately 6.6 per cent.

(c) Lamina cribrosa was present in $10 \cdot 2$ per cent.

(d) Physiological cup was present in 33.28 per cent. and absent in 27.04 per cent.

(e) Physiological cup was small in 39.67 per cent., shallow in 8.6 per cent., and showed shelving in $8 \cdot 3$ per cent.

A further analysis of the percentage incidence of the various features mentioned was carried out according to sex and age group, and the results

* Received for publication March 13, 1962. 
were recorded graphically. The figures recorded by the two observers showed a fair amount of variation but the two graphs were identical in form and the following points were observed:

(a) Venous pulsation was found to be more common in females of all ages. The percentages were higher in the age groups 16 to 35 , and the highest (27 per cent.) being recorded for age group 21 to 25 . In later age groups the figures for females approximated to those for males, though remaining approximately 3 per cent. higher. In males over 10 per cent. in age group 11 to 20 , was followed by a decline to 4 per cent. in age group 26 to 30 , and a subsequent rise to 18 per cent. in age group 61 to 65 .

(b) Glial tissue was found to be slightly more frequent in males than in females. The percentages varied from 1.5 per cent. in age group 21 to 25 to 15.5 per cent., in age group 41 to 45 . The higher percentages occurred in age groups 41 to 60 .

(c) Lamina cribrosa was seen more frequently in males. The highest incidence, 18 per cent., was recorded in age group 61 to 65 , and the lowest, 2.5 per cent., in age group 6 to 10. The higher percentages were noted in age group 51 to 65 .

(d) Physiological cupping was found to be absent slightly more frequently in females than in males. The average for different age groups was 28 per cent. as compared with 23 per cent. in males. The highest percentages were recorded in age groups 6 to 15 .

The fully-formed physiological cup (over 20 per cent. disc area) was noted more commonly in males (average 37 per cent.), than in females (average 30 per cent.). In both sexes the higher percentages were noted in age groups 21 to 30 , and 46 to 60 .

Small physiological cupping (less than 20 per cent. of the disc area) was noted very slightly more frequently in females than in males. The average was 36 per cent. The higher percentages were noted in age groups 6 to 25, and again in age groups 46 to 55, after which there was a steady reduction.

(e) In observing shallow physiological cupping there was a wide difference between the two observers, but the shape of the two graphs is similar. The percentages are higher for age groups 36 to 40 and 71 to 75 .

For shelved physiological cupping, the figures for the two observers are closer. This formation was slightly more frequent in females. The highest percentages were recorded for age groups 11 to 15 .

An analysis according to the presence of different refraction errors was carried out and graphs prepared which again showed differences in amplitude for the two observers although the shapes of the graphs were the same:

(1) Venous pulsation was seen most commonly in eyes with no astigmatic error.

(2) Lamina cribrosa was more common in eyes with no astigmatic error.

(3) Physiological cupping was absent most commonly in hypermetropic eyes, as was small physiological cupping.

(4) Large physiological cupping was noted most frequently in cases of myopic astigmatism and of myopia with astigmatism. 


\section{Conclusion}

The analysis according to age groups indicates that the pattern of the physiological cup changes, at least in some persons, in later life, i.e. from age 46 to 65 , when the clarity of the lamina cribrosa, glial tissue, and size of the cup are increased, indicating a loss of substance from the nervehead. The greater frequency of shelving of the disc in the age group 10 to 15 tends to support this observation.

We thank Mr. A. Barr and Mr. J. D. Golding of the Oxford Regional Hospital Board for their invaluable help in analysing these figures.

\section{REFERENCES}

BeDnaRSKI, A. (1954). Arch. Ophtal., 42, 5.

Pickard, R. (1921). Proc. roy. Soc. Med., 14, Sect. Ophthal., p. 31. (1923). Brit. J. Ophthal., 7, 81.

ThOMPson, A. H. (1920). Trans. ophthal. Soc. U.K., 40, 334.

Williamson-Noble, F. A. (1961). Ibid., 81, 437. 